\title{
Antifungal Activity of 2-Deoxy-D-Glucose on Botrytis cinerea, Penicillium expansum, and Rhizopus stolonifer: Ultrastructural and Cytochemical Aspects
}

\author{
Ahmed El-Ghaouth, Charles L. Wilson, and Michael Wisniewski
}

First author: Centre de Recherche en Horticulture, Université Laval, Quebec, G1K 7P4, Canada; and second and third authors: USDA, ARS, Appalachian Fruit Research Station, Kearneysville, WV 25530.

Accepted for publication 7 April 1997.

\begin{abstract}
El-Ghaouth, A., Wilson, C. L., and Wisniewski, M. 1997. Antifungal activity of 2-deoxy-D-glucose on Botrytis cinerea, Penicillium expansum, and Rhizopus stolonifer: Ultrastructural and cytochemical aspects. Phytopathology 87:772-779.

The effect of 2-deoxy-D-glucose on major postharvest pathogens was investigated at the ultrastructural and cytochemical level. Hyphae of Botrytis cinerea, Penicillium expansum, and Rhizopus stolonifer grown in the absence of 2-deoxy-D-glucose were normal and showed no apparent cytological alterations. In the presence of 2-deoxy-D-glucose, however, these fungi exhibited severe cellular injuries ranging from cell wall disruption to cytoplasm disintegration. Although 2-deoxy-D-glucose caused

cytoplasmic degeneration in the three fungi tested, cell wall alterations were exhibited only by $B$. cinerea and $R$. stolonifer. In the latter, the retraction of degenerated cytoplasm was often accompanied by the deposition of amorphous material in paramural spaces. Cytochemical study of fungal cell wall components showed that 2-deoxy-D-glucose caused a marked increase of chitin- and $\beta$-1,3-glucan-labeling in $R$. stolonifer and $B$. cinerea, indicating an interference of 2-deoxy-D-glucose with fungal wall biosynthesis. The observed cellular alterations indicate that 2-deoxy-Dglucose may also have affected other metabolic processes.

Additional keywords: nonmetabolizable sugars, postharvest biocontrol, sugar analogs.
\end{abstract}

Postharvest diseases of fruits and vegetables cause major losses in food production. Currently, fungicides represent the primary means of controlling postharvest diseases $(7,13)$. However, public concerns over the presence of chemical residues in the food chain and the development of fungicide-resistant strains of postharvest pathogens have generated an urgent need for the development of safer alternative technologies (15). The sugar analog 2-deoxy-Dglucose may meet this need; it has been shown to interfere with the growth of several postharvest pathogens and provides partial control over decay of apple and peach fruit (9). When tested in vitro, 2-deoxy-D-glucose inhibited the radial growth of several postharvest pathogens and caused morphological alterations in Rhizopus stolonifer (Ehrenb.:Fr.) Vuill. and Botrytis cinerea Pers.:Fr. (9).

Sugar analogs are known to inhibit the growth of several yeasts and some filamentous fungi in the absence of metabolizable sugars $(1,2,6,10)$. In yeast, the inhibitory effect of compounds like 2deoxy-D-glucose has been associated with the compound's ability to interfere with the metabolic processes implicated in cell wall biosynthesis, such as $\beta$-1,3-glucan formation $(6,10,11)$. Although there is a considerable literature on the biochemical basis of the inhibitory effect of 2-deoxy-D-glucose in yeasts $(11,12,14)$, there has not been detailed analysis of its effects on plant pathogenic fungi, particularly postharvest pathogens. The current study was undertaken to gain more information regarding the cytochemical effect of 2-deoxy-D-glucose on major postharvest pathogens. Particular emphasis was placed on the effect of 2-deoxy-D-glucose on cell wall composition.

Corresponding author: A. El-Ghaouth; E-mail address: ghaouth@asrr.arsusda.gov

Publication no. P-1997-0505-02R

This article is in the public domain and not copyrightable. It may be freely reprinted with customary crediting of the source. The American Phytopathological Society, 1997.

\section{MATERIALS AND METHODS}

Reagents and microorganisms. Colloidal gold suspension was purchased from Electron Microscopy Sciences (Fort Washington, PA), and Spurr's epoxy resin was obtained from Polysciences, Inc. (Warrington, PA). The sugar analog 2-deoxy-D-glucose, purified lyticase, and all other reagents were purchased from Sigma Chemical Co. (St. Louis). Isolates of $R$. stolonifer, Penicillium expansum Link, and $B$. cinerea were isolated from infected fruits and maintained on potato dextrose agar (PDA).

Cytological effect of 2-deoxy-D-glucose. The effect of 2-deoxyD-glucose on $B$. cinerea, $R$. stolonifer, and $P$. expansum was studied by growing these fungi on PDA amended with $0.1 \%$ (wt/vol) 2-deoxy-D-glucose. Previous studies showed that 2-deoxy-D-glucose at a concentration of $10 \mathrm{mg} / \mathrm{ml}$ caused morphological alterations in $B$. cinerea and $R$. stolonifer without complete inhibition of radial growth (9). Sterile molten PDA was amended with a membrane-sterilized solution of 2-deoxy-D-glucose to obtain concentrations of 0 or $0.1 \%$ (wt/vol) 2-deoxy-D-glucose, and then dispensed immediately into 9 -cm-diameter polystyrene petri plates. After cooling, each plate was inoculated with a 6-mm-diameter mycelial plug from the margin of a 4-day-old $B$. cinerea, 2-dayold $R$. stolonifer, or 7-day-old $P$. expansum culture, and the plates were incubated in the dark at $24^{\circ} \mathrm{C}$ for $72 \mathrm{~h}$. Four replicate plates were used for each fungus at each concentration of 2-deoxy-Dglucose and, from each replicate plate, two mycelial samples from the margin of the cultures were processed for ultrastructural and cytochemical studies for a total of $n=8$.

Tissue processing. Mycelial samples $\left(1.0 \mathrm{~mm}^{2}\right)$ were incubated for $2 \mathrm{~h}$ at $4^{\circ} \mathrm{C}$ in $3 \%(\mathrm{vol} / \mathrm{vol})$ glutaraldehyde in $25 \mathrm{mM}$ sodium phosphate buffer ( $\mathrm{pH}$ 6.8) and rinsed with the same buffer. Thereafter, samples were dehydrated in a graded ethanol series, and then embedded in Spurr's epoxy resin. Half of the samples were postfixed for $1 \mathrm{~h}$ at $4^{\circ} \mathrm{C}$ in $1.0 \%$ (wt/vol) osmium tetroxide 
in $25 \mathrm{mM}$ sodium phosphate buffer ( $\mathrm{pH}$ 6.8) prior to dehydration. Ultrathin sections, collected on nickel grids (200 mesh), were contrasted with uranyl acetate and lead citrate before examination with a Hitachi H-600 transmission electron microscope (Nissei Sangyo American, Mountain View, CA) at $75 \mathrm{kV}$, or processed for cytochemical labeling prior to examination. For each fungus at each concentration of 2-deoxy-D-glucose, an average of five blocks from four of the eight total samples were sectioned. For each sample, at least 10 ultrathin sections were examined.

Preparation of gold-conjugated probes. A commercially purified lyticase with endoglucanase activity was used to determine the distribution of $\beta$-1,3-glucan in the cell walls of $B$. cinerea and P. expansum. The estimated optimal $\mathrm{pH}$ was 5.0 , and the minimum amount of enzyme needed to stabilize the gold solution was $5.0 \mu \mathrm{g} / \mathrm{ml}$ according to a method described previously (3, 5). Lyticase-gold complex was prepared by adding $100 \mu \mathrm{g}$ of enzyme to $10 \mathrm{ml}$ of colloidal gold, $\mathrm{pH} 5.0$. The solution was further stabilized with a few drops of $1.0 \%$ (wt/vol) polyethylene glycol 20,000, centrifuged at $4{ }^{\circ} \mathrm{C}(60 \mathrm{~min}, 12,000 \times \mathrm{g})$, and the pellet was suspended in $0.5 \mathrm{ml}$ of phosphate-buffered saline (PBS), $\mathrm{pH} 7.3$, containing Tween 20. Lyticase-gold complex was stored at $4^{\circ} \mathrm{C}$.

Wheat germ agglutinin (WGA), a lectin with binding specificity to $N$-acetylglucosamine, was used to study the distribution of chitin within the wall of B. cinerea, $R$. stolonifer, and P. expansum. Because of its low molecular mass, WGA could not be complexed directly to gold. Therefore, ovomucoid, a glycoprotein with high affinity for WGA, was conjugated to colloidal gold and used as a second step reagent $(4,8)$.

Cytochemical labeling. For direct labeling of $\beta$-1,3-glucan, ultrathin sections from samples fixed in either glutaraldehyde or glutaraldehyde and osmium tetroxide were first floated for $5 \mathrm{~min}$ on a drop of $10 \mathrm{mM}$ PBS ( $\mathrm{pH} 7.3$ ) containing Tween 20. Thereafter, the sections were transferred to a drop of lyticase-gold complex for $30 \mathrm{~min}$ at room temperature in a moist chamber. After rinsing thoroughly with PBS ( $\mathrm{pH}$ 7.4) and then with double-distilled water, grids were contrasted with uranyl acetate and lead citrate. For indirect labeling of chitin, sections were incubated on a drop of WGA $(25 \mu \mathrm{g} / \mathrm{ml})$ in PBS ( $\mathrm{pH} 7.2)$ for $30 \mathrm{~min}$ at room temperature, rinsed with PBS, and transferred to a drop of ovomucoid-gold complex for $30 \mathrm{~min}$. After rinsing with PBS and double-distilled water, sections were contrasted and examined with a Hitachi $\mathrm{H}-$ 600 transmission electron microscope at $75 \mathrm{kV}$.

Specificity of the different labels was verified using the following control tests: (i) incubation of sections with lyticase-gold complex to which was previously added one of the following polysaccharides (laminarin, laminaribiose, $N$-acetylchitotriose, $\beta$ 1,4-glucan from barley, or polygalacturonic acid at a concentration of $1.0 \mathrm{mg} / \mathrm{ml}$ ); (ii) incubation of sections with uncomplexed lyticase, followed by gold-complexed lyticase; (iii) incubation of sections with bovine serum albumin-gold complex; (iv) incubation of sections with WGA, previously adsorbed with $\mathrm{N}$-acetylchitotriose followed by incubation with ovomucoid-gold complex; (v) incubation of sections with WGA, followed by uncomplexed ovomucoid, and finally by ovomucoid-gold complex; and (vi) direct incubation with ovomucoid-gold complex, the WGA step being omitted.

\section{RESULTS}

Cytological effect of 2-deoxy-D-glucose. The main aspects of the effect of 2-deoxy-D-glucose on the morphology of $B$. cinerea, $R$. stolonifer, and $P$. expansum have been previously described (9). In brief, 2-deoxy-D-glucose treatment caused severe morphological alterations such as excessive branching and hyphal swelling in the three fungi tested. Among the fungi tested, R. stolonifer appeared to be the most sensitive to 2-deoxy-D-glucose. To further determine whether the morphological alterations caused by 2-deoxy-D-glucose are due to its effect on fungal cell wall formation, cytological studies were undertaken. In the absence of 2-deoxy-D-glucose, $R$. stolonifer, B. cinerea, and $P$. expansum hyphae were delimited by a thin, electron, opaque wall against which the plasma membrane was closely appressed (Figs. 1-4, section A). The presence of polysome-rich cytoplasm with numerous organelles such as mitochondria and nuclei indicated a high level of metabolic activity.

Examination of sections from $R$. stolonifer, $B$. cinerea, and $P$. expansum grown in the presence of 2-deoxy-D-glucose showed that 2-deoxy-D-glucose caused severe cell wall and cytoplasmic damage to the three fungi tested. $R$. stolonifer exposed to 2-deoxyD-glucose often displayed pronounced cellular disorganization that ranged from disruption of the wall to marked cytoplasmic degeneration (Fig. 1B-D). The affected Rhizopus cells were generally surrounded by swollen, distorted cell walls, and the cytoplasm appeared highly altered with no discernible organelles (Fig. 1B and D). In many cases, an increase in the formation of lipid bodies was observed (Fig. 1B).

The cell wall and cytoplasmic alterations caused by 2-deoxy-Dglucose were usually followed by the retraction of plasma membrane and the deposition of amorphous material in the paramural space (Fig. 1C and D). This material appeared less compact and electron-dense than the cell wall (Fig. 1C). Numerous vesicles were observed in the newly deposited material (Fig. 1C and D). In extreme cases, the deposited material extended inward, compressing the highly vesiculated cytoplasm (Fig. 1D). In these cells, the convoluted plasma membrane was retracted from the cell wall (Fig. 1D).

Cytological alterations were also exhibited by $B$. cinerea and $P$. expansum cells grown in the presence of 2-deoxy-D-glucose. In the absence of 2-deoxy-D-glucose, Botrytis cells were delimited by a thin, electron, opaque wall against which the plasma membrane was closely appressed (Fig. 2A and C). Again, the presence of a polysome-rich cytoplasm with numerous organelles was suggestive of intense metabolic activity. By contrast, $B$. cinerea grown in the presence of 2-deoxy-D-glucose displayed various levels of cellular disorganization that ranged from cell wall disruption to cytoplasmic disintegration (Fig. 2B, D, and E). Botrytis cells often showed a marked increase in cell wall thickness and, in many cases, cytoplasmic integrity was lost (Fig. 2B and D). Walls of Botrytis cells exposed to 2-deoxy-D-glucose often appeared swollen and distorted (Fig. 2B and E). The gradual retraction and disintegration of the cytoplasm was a common characteristic of hyphal cells grown in the presence of 2-deoxy-D-glucose (Fig. 2D and E). Such changes, however, were not followed by the deposition of amorphic material in the paramural spaces.

Cytochemical localization of chitin. To determine whether the observed fungal wall alterations caused by 2-deoxy-D-glucose were the result of a change in cell wall composition, ultrathin sections were treated with WGA-gold complex (a lectin with $\mathrm{N}$-acetylglucosamine-binding specificity). Application of WGA-gold complex to ultrathin sections of $R$. stolonifer grown in absence of 2-deoxy-D-glucose resulted in a specific deposition of gold particles over cell walls (Fig. 3A). Labeling was very light and mainly associated with the outer wall layers of $R$. stolonifer (Fig. 3A, arrow). Specific labeling of the cell wall by WGA-ovomucoidgold complex was also observed in $R$. stolonifer grown in the presence of 2-deoxy-D-glucose (Fig. 3B-D). Close examination of $R$. stolonifer cells grown in the presence of 2-deoxy-D-glucose showed an unusual distribution of chitin (Fig. 3B-D). In vacuolated $R$. stolonifer cells, the gradual retraction of the cytoplasm resulted in the sequential deposition of amorphic material in paramural spaces (Fig. 3B). An intense accumulation of gold granules was observed over the newly formed material (Fig. 3B and C). In some R. stolonifer cells, the newly formed chitin-rich material extended inward, cleaving the damaged cytoplasm (Fig. 3D, arrow). Gold-labeling was absent over sections treated with WGA-ovomucoid-gold complex previously adsorbed with $N$-acetylchitotriose (data not shown). 
Incubation of ultrathin sections from $B$. cinerea grown on PDA in the absence or presence of 2-deoxy-D-glucose with WGA-gold complex resulted also in a specific deposition of gold particles over the cell walls (Fig. 2C-E). Chitin-labeling was more intense over the walls of Botrytis cells exposed to 2-deoxy-D-glucose (Fig. 2E) than of the control grown on PDA alone (Fig. 2C). An intense and regular deposition of gold particles was detected over swollen walls of affected Botrytis cells (Fig. 2D and E). Degener- ated cytoplasm and paramural spaces were almost free from labeling. However, in P. expansum, the structural integrity of the wall and the distribution of chitin did not seem to be affected by 2-deoxy-D-glucose. Although Penicillium cells exposed to 2-deoxy-D-glucose showed pronounced cytoplasmic alterations, no cell wall damage was observed (Fig. 4B). The affected Penicillium cells with degenerating cytoplasm were generally surrounded by a thin cell wall with no apparent signs of alteration (Fig. 4B). The inten-
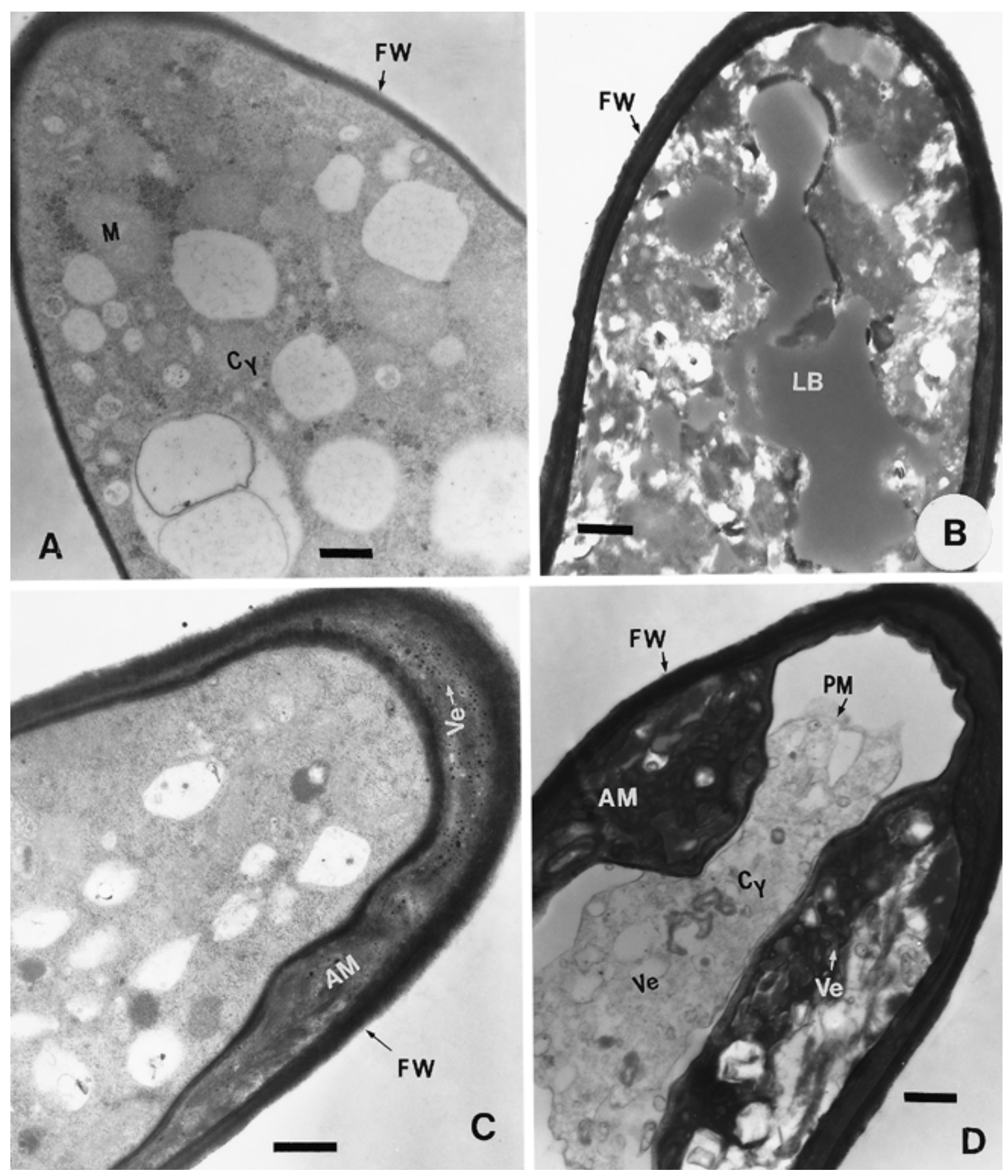

Fig. 1. Transmission electron micrographs of Rhizopus stolonifer. A, R. stolonifer hypha grown on medium lacking 2-deoxy-D-glucose. Hypha is delimited by a thin wall and its polysome-rich cytoplasm contains numerous organelles. B-D, R. stolonifer hyphae grown on potato dextrose agar medium containing $0.1 \%$ (wt/vol) 2-deoxy-D-glucose. R. stolonifer cells show $\mathbf{B}$, thickening of the cell wall and disintegration of the cytoplasm; $\mathbf{C}$, the formation of cell wall-like material in the paramural spaces; and, in some cases, D, the de novo wall synthesis extended inward toward the degenerating cytoplasm. Note the numerous inclusion vesicles in the newly deposited material and the highly distorted plasma membrane. Abbreviations: $\mathrm{AM}=$ amorphous material, $\mathrm{Cy}=\mathrm{cytoplasm}, \mathrm{F}=\mathrm{fungal}$ cell, $\mathrm{FW}=$ fungal cell wall, $\mathrm{LB}=$ lipid body, $\mathrm{M}=$ mitochondria, $\mathrm{PM}=$ plasma membrane, $\mathrm{S}=$ septum, and $\mathrm{Ve}=$ vesicle $. \mathrm{Bar}=0.5 \mu \mathrm{m}$. 
sity and pattern of chitin-labeling observed in the Penicillium cells grown on PDA alone (Fig. 4A) were similar to that of the cells exposed to 2-deoxy-D-glucose (Fig. 4B).

Cytochemical localization of $\beta$-1,3-glucan. A purified lyticase with endoglucanase activity was complexed to colloidal gold at $\mathrm{pH} 5.0$ and used to study the distribution of $\beta$-1,3-glucan. The analyses of the purified lyticase after sodium dodecyl sulfate-polyacrylamide gel electrophoresis showed one single band with a molecular mass estimated at $57 \mathrm{kDa}$. The labeling pattern and intensity obtained with lyticase-gold complex was not affected by the fixation process. Fungal cells fixed in either glutaraldehyde or glutaraldehyde and osmium tetroxide displayed similar labeling patterns.

Treatment of sections of $R$. stolonifer, $P$. expansum, and B. cinerea grown on PDA in the presence or absence of 2-deoxy-D-glucose with lyticase-gold complex resulted in a deposition of gold particles over the sectioned walls of $P$. expansum and $B$. cinerea (Figs. 4C-E and 5A-C). There was no labeling of the cytoplasm. No labeling of the cell wall of $R$. stolonifer was observed, indicating the absence of recognition sites. With $P$. expansum, the severe cytoplasmic damage caused by 2-deoxy-D-glucose did not result in any alteration in the distribution of $\beta$-1,3-glucan in the cell wall. The intensity and distribution of $\beta$-1,3-glucan-labeling over cell walls of $P$. expansum exposed to 2-deoxy-D-glucose (Fig. 4D and E) was similar, in many respects, to that of the Penicillium cells grown on PDA alone (Fig. 4C).

The most marked changes in $\beta$-1,3-glucan deposition in response to 2-deoxy-D-glucose treatment were observed in B. cinerea. Exposure of $B$. cinerea to 2-deoxy-D-glucose appeared to increase $\beta$-1,3-glucan-labeling (Fig. 5B). B. cinerea cells grown in the presence of 2-deoxy-D-glucose showed an intense labeling of $\beta$-1,3-glucan over highly swollen walls (Fig. 5B and C). Gold granules were rarely detected in degenerating cytoplasm or paramural spaces caused by retraction of the cytoplasm (Fig. 5B and C). Several tests were conducted to determine the specificity of labeling patterns obtained with lyticase-gold complex. Among the polysaccharides tested, only laminarin and laminaribiose prevented gold-labeling when preincubated with lyticase-gold complex (Fig. 5D). No labeling was observed when sections were
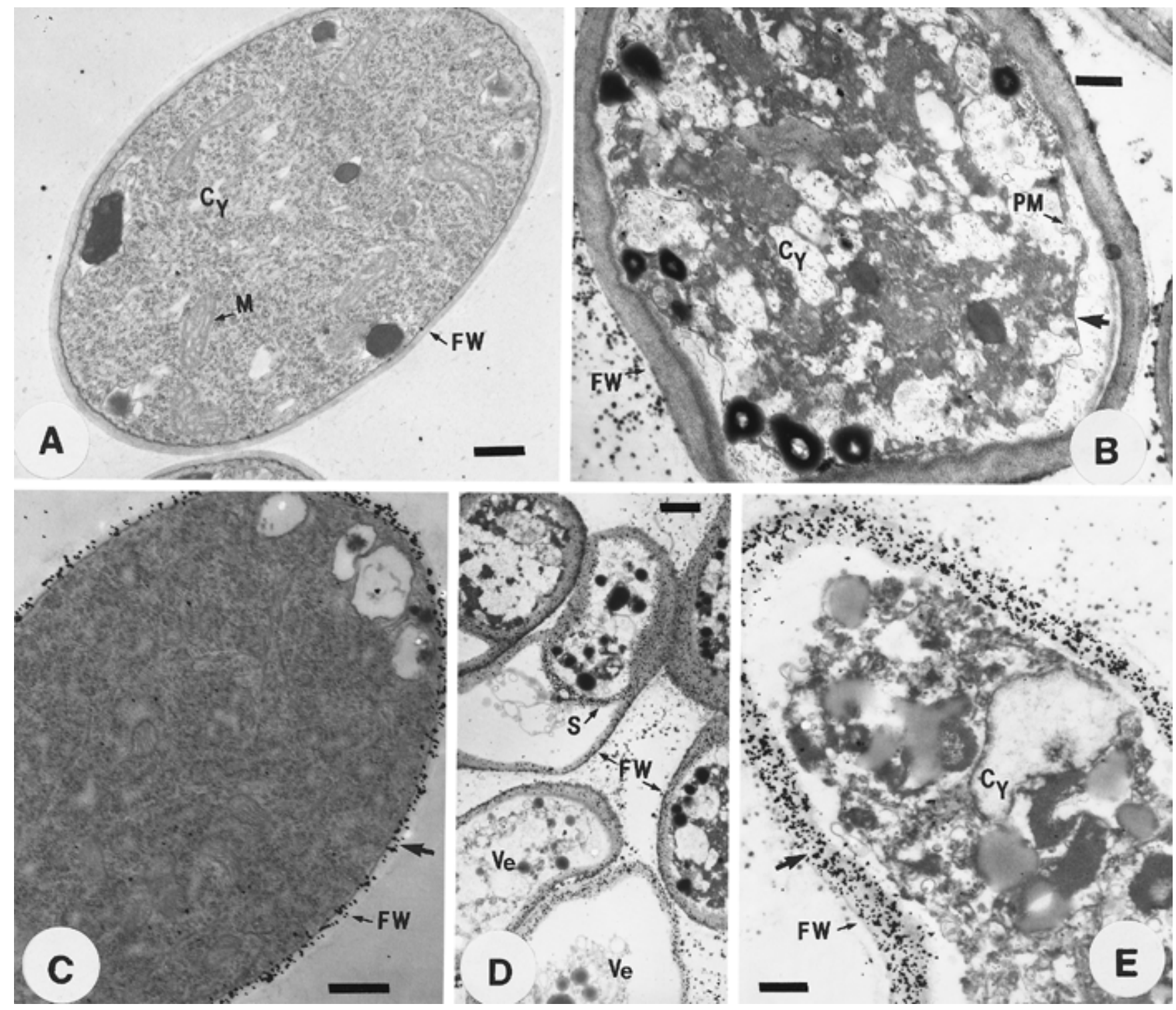

Fig. 2. Transmission electron micrographs of Botrytis cinerea. A, B. cinerea hypha grown on medium lacking 2-deoxy-D-glucose. A cell of B. cinerea surrounded by a thin wall and containing numerous organelles in the cytoplasm. B, B. cinerea hypha grown on potato dextrose agar (PDA) medium containing $0.1 \%$ (wt/vol) 2-deoxy-D-glucose. Note the extensive swelling of the cell wall and degeneration of the cytoplasm. C-E, Labeling of chitin with wheat germ agglutinin (WGA)-ovomucoid-gold complex. C, B. cinerea hypha grown on medium lacking 2-deoxy-D-glucose. Incubation with WGA-ovomucoid-gold complex resulted in a preferential deposition of gold particles over the cell wall. Cytoplasm and organelles were free from labeling. D and E, B. cinerea hyphae grown on PDA medium containing $0.1 \%$ (wt/vol) 2-deoxy-D-glucose. In damaged fungal cells, intense chitin-labeling was observed over swollen walls. Note the retraction of the cytoplasm and convolution of the plasma membrane in $\mathbf{E}$. Bar $=0.5 \mu \mathrm{m}$. 
treated with laminarase or lyticase prior to incubation with lyticase-gold complex (data not shown).

\section{DISCUSSION}

Recently, 2-deoxy-D-glucose was shown to effectively reduce postharvest decay in apple and peach fruit (9). The control of postharvest decay by 2-deoxy-D-glucose was associated with its antifungal activity. An in vitro study showed that 2-deoxy-D-glucose inhibited mycelial growth of Monilinia fructicola, $R$. stolonifer, $P$. expansum, and B. cinerea and caused severe morphological alterations in $B$. cinerea and $R$. stolonifer. The inhibitory effect of 2-deoxy-D-glucose is well established and has been extensively studied in yeast $(6,10,11)$. In the current study, we show that 2-deoxy-D-glucose caused pronounced ultrastructural alterations in $B$. cinerea, $P$. expansum, and $R$. stolonifer and affected cell wall composition in $B$. cinerea and $R$. stolonifer.

In the three fungi tested, 2-deoxy-D-glucose caused severe cellular disorganization that ranged from cytoplasmic retraction to complete protoplasm disintegration, thus indicating that it might have impaired cellular metabolism. Similar cytoplasmic altera- tions were reported in Neurospora crassa exposed to another sugar analog, L-sorbose (14). The cytoplasmic degeneration observed in the fungi exposed to 2-deoxy-D-glucose could be the consequence of the interference by the phosphate ester of 2-deoxyD-glucose with energy-yielding metabolic processes. Sugar analogs like 2-deoxy-D-glucose that readily form phosphate esters are known to inhibit glycolytic enzymes, deplete cellular supplies of ATP and, thereby, affect metabolic processes that are regulated by energy charge or dependent on nucleotide pools (11).

In addition to causing severe cytoplasmic damage in the fungi tested, 2-deoxy-D-glucose also caused pronounced cell wall changes in $R$. stolonifer and $B$. cinerea. While the cell wall of $P$. expansum grown in the presence of 2-deoxy-D-glucose showed no obvious changes, hyphal walls of $R$. stolonifer and $B$. cinerea cells appeared swollen. Wall alteration appeared more severe in $R$. stolonifer, in which the retraction of the plasma membrane was often followed by the formation of an amorphous material in the paramural space. Similar swelling of cell walls was observed in yeast and some filamentous fungi exposed to sugar analogs $(6,10$, 12,14). In yeast, 2-deoxy-D-glucose causes the erosion of preformed wall material and prevents the synthesis of new wall components,

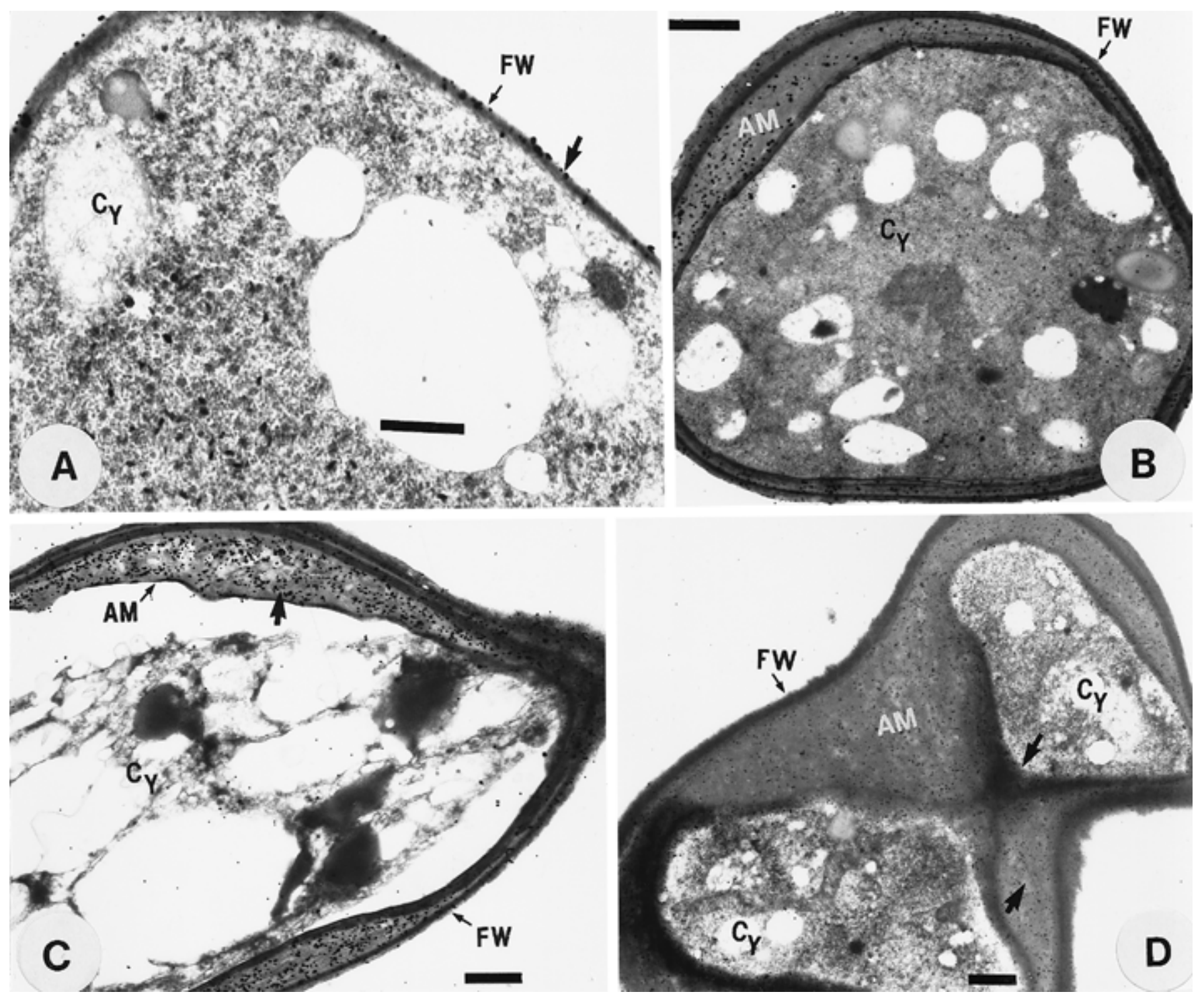

Fig. 3. Transmission electron micrographs of Rhizopus stolonifer. Labeling of chitin with wheat germ agglutinin (WGA)-ovomucoid-gold complex. A, R. stolonifer hypha grown on medium lacking 2-deoxy-D-glucose. Incubation with WGA-ovomucoid-gold complex resulted in a light deposition of gold particles in the outermost wall layer. B-D, $R$. stolonifer hyphae grown on potato dextrose agar medium containing $0.1 \%$ (wt/vol) 2-deoxy-D-glucose. B and C, Gold particles tended to accumulate in swollen cell walls and in newly deposited material. C, Gold-labeling appeared more intense in newly deposited material than in the existing but altered wall. D, Chitin-rich material has extended inward, splitting the degenerating cytoplasm. Bar $=0.5 \mu \mathrm{m}$. 
namely $\beta$-1,3-glucan $(6,11)$. Detailed analysis of the effect of 2deoxy-D-glucose on various cell wall components of filamentous fungi has not been undertaken. Whether the swelling of the fungal cell wall is a primary effect of 2-deoxy-D-glucose or a consequence of metabolic disturbance warrants further investigation.

It is possible that the wall swelling observed in $R$. stolonifer and $B$. cinerea resulted from the interference of 2-deoxy-D-glucose with fungal cell wall biosynthesis and construction. This is supported, in part, by the cytochemical observations made in the current study (Figs. 2B-D, 3D and E, and 5B and C). Analysis of chitin and $\beta$-1,3-glucan distribution in the walls of $R$. stolonifer and $B$. cinerea showed an increase in chitin- and $\beta$-1,3-glucan-labeling of altered walls. In $R$. stolonifer, the newly formed paramural material displayed a strong chitin-labeling pattern, suggesting that 2-deoxy-D-glucose or its derivatives may have induced chitin biosynthesis. Alternatively, the increase in chitin- and $\beta$-1,3-glucanlabeling of altered walls of $R$. stolonifer and $B$. cinerea could be the result of an increase in accessibility of chitin and $\beta$-1,3-glucan components of the fungal wall. Wall disruption can be expected to interfere with cross-linking between major cell wall components, chitin and $\beta$-1,3-glucan, consequently rendering them more accessible. Detailed analysis of the effect of 2-deoxy-D-glucose on chitin and $\beta$-1,3-glucan synthesis may provide further insight concerning
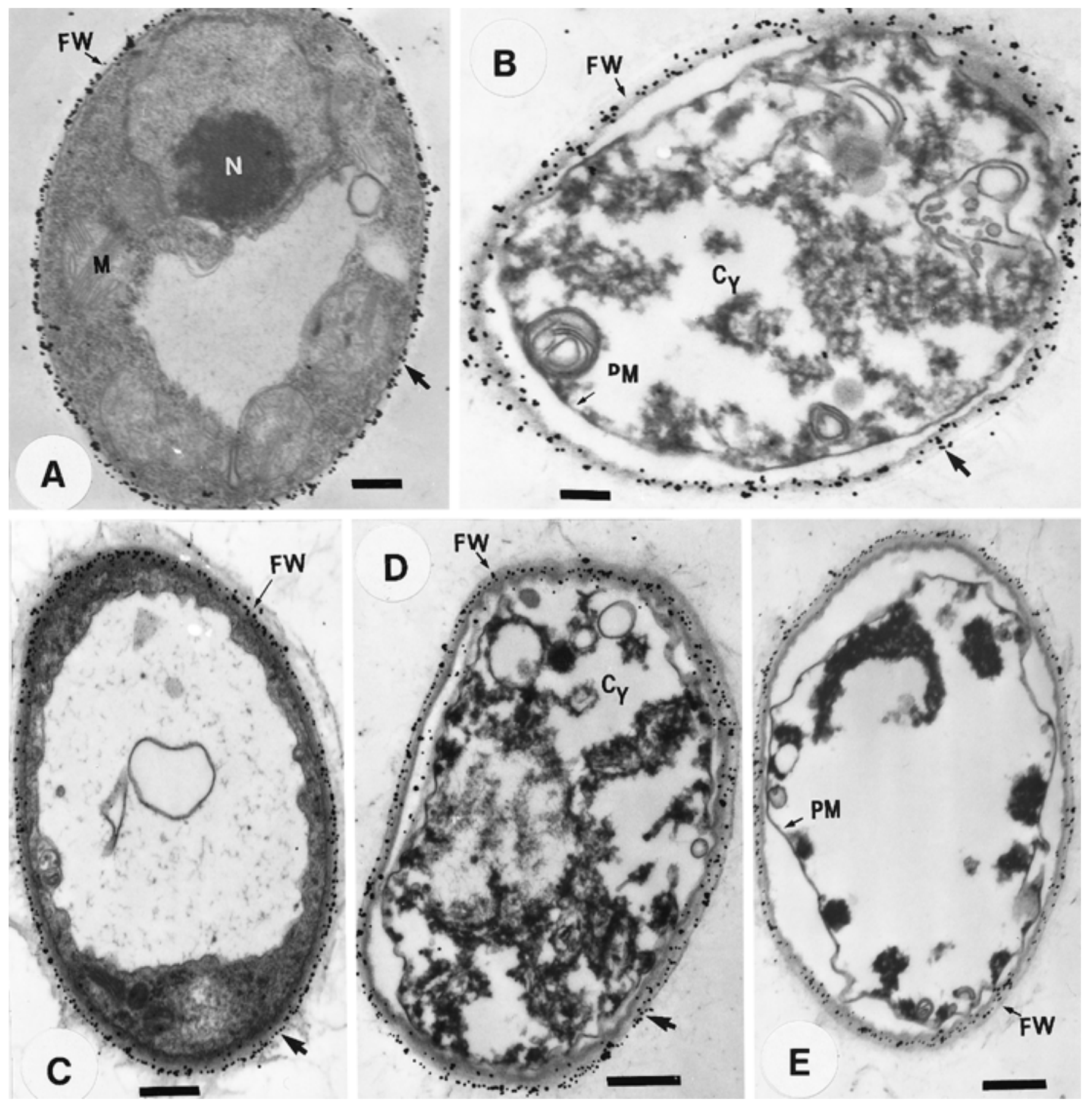

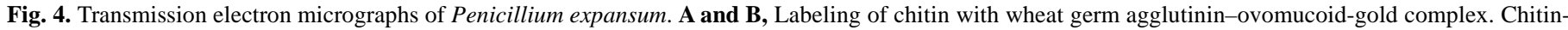

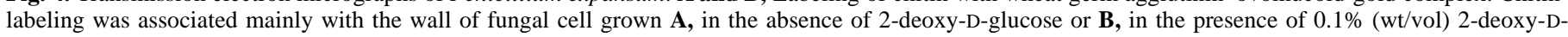

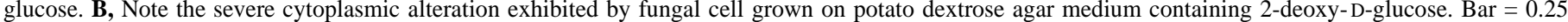

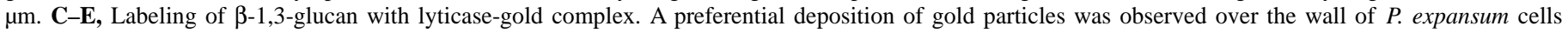

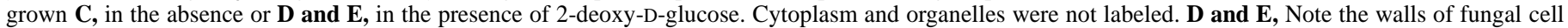
with contracted or completely disrupted protoplasm showed no apparent sign of alteration. Bar $=0.5 \mu \mathrm{m}$. 
the effect of 2-deoxy-D-glucose on the balance between the biosynthesis and turnover of chitin and $\beta$-1,3-glucan.

Although 2-deoxy-D-glucose was shown to inhibit glucan formation and greatly increase the osmotic fragility of yeast cells and some fungi $(6,11,16)$, no apparent changes in $\beta$-1,3-glucan-labeling were observed over the walls of $B$. cinerea and $P$. expansum grown in the presence of 2-deoxy-D-glucose at a concentration that caused severe cytoplasmic alterations. This divergence may be due to the difference in the ratio of 2-deoxy-D-glucose to utilizable sugar in the growth medium and between the microorganisms used. In Saccharomyces cerevisiae and Aspergillus nidulans, the inhibition of $\beta$-1,3-glucan synthesis by 2 -deoxy-D-glucose was observed in media lacking utilizable sugars $(6,11,16)$. Furthermore, differential sensitivity of microorganisms to sugar analogs like 2-
deoxy-D-glucose has been demonstrated and is partly attributed to a difference in the affinity of transport systems for different sugar analogs (11). Differential sensitivity to 2-deoxy-D-glucose was also observed in the current study in which $P$. expansum, unlike $R$. stolonifer and $B$. cinerea, did not exhibit any apparent alteration in cell wall composition as indicated by chitin- and $\beta-1,3$-glucan-labeling.

In conclusion, this study demonstrates that 2-deoxy-D-glucose affects cell wall integrity and construction in major postharvest pathogens. This suggests that the reduction of postharvest decay by 2-deoxy-D-glucose may be associated with its ability to cause severe cellular damage in major postharvest pathogens. This biocidal compound could have potential as antifungal preservative for fresh commodities once its safety for human consumption has been established.
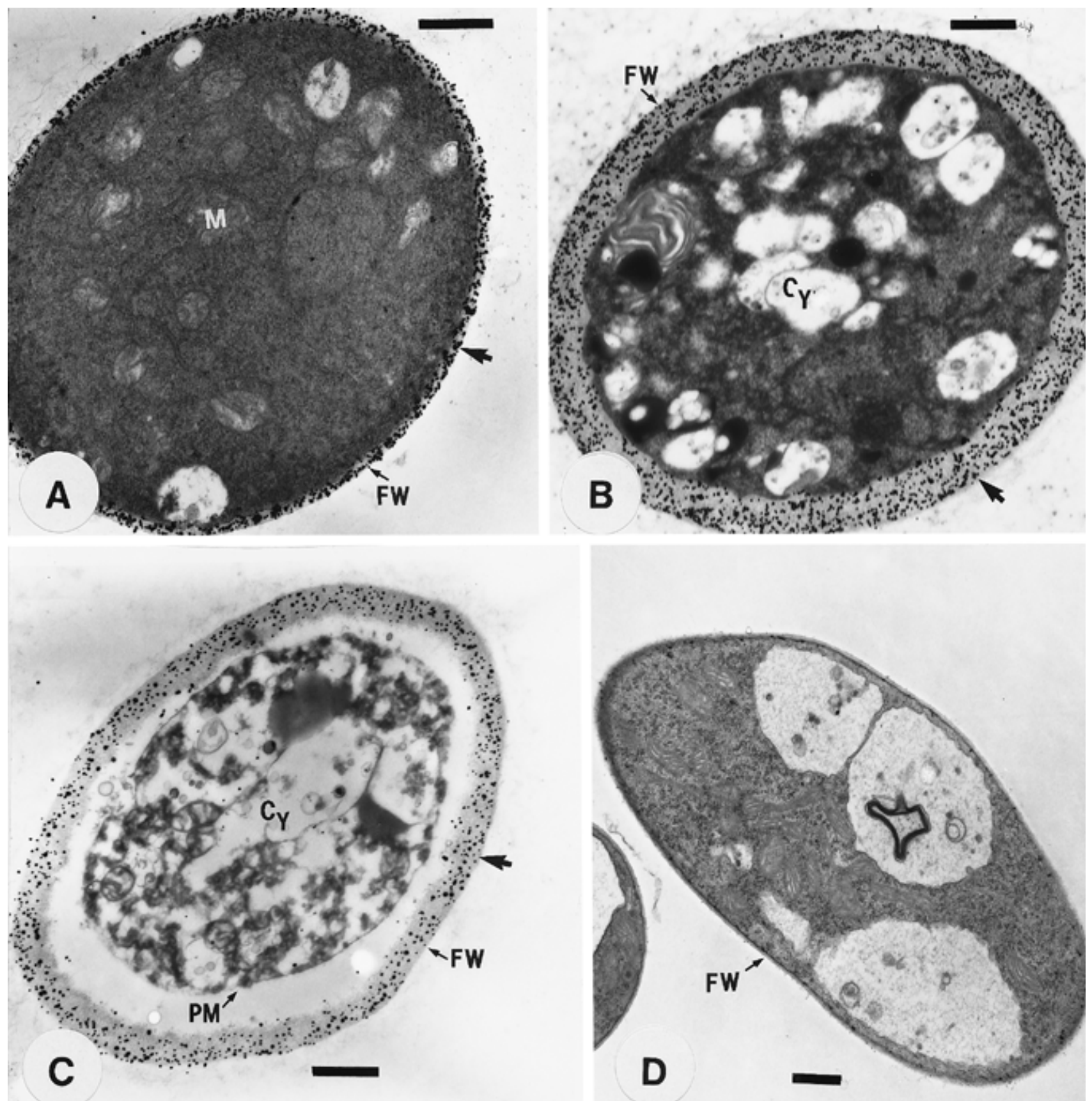

Fig. 5. Transmission electron micrographs of Botrytis cinerea. Labeling of $\beta$-1,3-glucan with lyticase-gold complex. A, B. cinerea hypha grown on medium lacking 2-deoxy-D-glucose. Incubation with lyticase-gold complex resulted in a preferential deposition of gold particles over the cell wall. Cytoplasm and organelles were free from labeling. B and C, B. cinerea hyphae grown on potato dextrose agar medium containing $0.1 \%$ (wt/vol) 2-deoxy-D-glucose. Swollen wall of fungal cell with $\mathbf{B}$, contracted or $\mathbf{C}$, disrupted protoplasm show an intense labeling of $\beta-1,3$-glucan. D, Control. Incubation with lyticase-gold complex, to which laminarin $(1.0 \mathrm{mg} / \mathrm{ml})$ was previously added, did not resulted in labeling. Bar $=0.5 \mu \mathrm{m}$. 


\section{LITERATURE CITED}

1. Atkin, R. K., Spencer, D. M., and Wain, R. L. 1964. Investigators of fungicides X. The antifungal activity of 2-deoxy-D-glucose. Ann. Appl. Biol. 53:437-443.

2. Barnett, H. L., and Lilly, U. G. 1951. The inhibitors effect of sorbose on fungi. Science 114:439-444.

3. Bendayan, M. 1987. Introduction of the protein G-complex for high resolution immuno-cytochemistry. J. Electron Microsc. Technol. 6: 7-18.

4. Benhamou, N. 1989. Preparation and application of lectin-gold complex. Pages 95-143 in: Colloidal Gold: Principles, Methods, and Applications. M. A. Hayat, ed. Academic Press, New York.

5. Benhamou, N. 1992. Ultrastructural detection of $\beta$-1,3-glucans in tobacco root tissues infected by Phytophthora parasitica var. nicotiana using a gold-complexed tobacco $\beta$-1,3-glucanase. Physiol. Mol. Plant Pathol. 41:1351-1370.

6. Biely, P., Krátky, Z., Kovark, J., and Bauer, S. 1971. Effect of 2-deoxyglucose on cell wall formation in Saccharomyces cerevisiae and its relation to cell growth inhibition. J. Bacteriol. 107:121-129.

7. Eckert, J. W., and Ogawa, J. M. 1988. The chemical control of postharvest diseases: Deciduous fruits, berries, vegetables and roots/tuber crops. Annu. Rev. Phytopathol. 26:433-469.

8. El Ghaouth, A., Arul, J., Asselin, A., and Benhamou, N. 1992. Antifungal activity of chitosan on post-harvest pathogens: Induction of morphological and cytological alterations in Rhizopus stolonifer. Mycol.
Res. 96:769-779.

9. El Ghaouth, A., Wilson, C. L., and Wisniewski, M. E. 1995. Sugar ana$\operatorname{logs}$ as potential fungicides for postharvest pathogens of apple and peach. Plant Dis. 79:254-258.

10. Krátky, Z., Biely, P., and Bauer, S. 1975. Mechanism of 2-deoxy-D-glucose inhibition of cell wall polysaccharide and glycoprotein biosynthesis in Saccharomyces cerevisiae. Eur. J. Biochem. 54:459-467.

11. Moore, D. 1981. Effect of hexose analogs on fungi: Mechanisms of inhibition and resistance. New Phytol. 87:487-515.

12. Moore, D., and Stewart, G. R. 1972. Effect of 2-D-glucosamine, and Lsorbose on growth of Coprinus lagopus hyphae. J. Gen. Microbiol. 71: 333-342.

13. Sommer, N. F. 1985. Strategies for control of postharvest diseases of selected commodities. Pages 83-99 in: Postharvest Technology of Horticultural Crops. A. Kader, R. F. Kasmire, F. G. Mitchell, M. S. Reid, N. F. Sommer, and J. F. Thompson, eds. Cooperative Extension, University of California, Davis.

14. Trinci, A. P. J., and Collinge, A. 1973. Influence of L-sorbose on the growth and morphology of Neurospora crassa. J. Gen. Microbiol. 78: 179-192.

15. Wisniewski, M. E., and Wilson, C. L. 1992. Biological control of postharvest diseases of fruits and vegetables, recent advances. HortScience 27:49-98.

16. Zonneveld, B. J. M. 1973. Inhibitory effect of 2-deoxyglucose on cell wall $\beta$-1,3-glucan synthesis and cleistothecium development in Aspergillus nidulans. Dev. Biol. 34:1-8. 